\title{
To Vote or Not To Vote: Marketing Factors Influencing the Voting Intention of University Students in Johannesburg
}

\author{
Anjali Morar, *Marike Venter, Tinashe Chuchu \\ University of the Witwatersrand, South Africa \\ *marike.venter@wits.ac.za
}

\begin{abstract}
Voting intention has become an issue of concern worldwide with regard to successful political elections. With only $6 \%$ of South Africa's youth having registered to vote in the 2014 elections, it is of vital importance to get a better understanding of the main reasons behind these statistics and factors that have influenced voting intentions. Although several studies have explored this area of research, it remains a topic of interest. This research paper aims to examine the factors behind voting intention of the youth in South Africa, as most are in their first or second democratic election. This study adds to existing literature on political parties as brands and factors influencing the youth's intention to vote. These factors include advertising mediums, convenience factors of location and registration, and social pressures from peers or family on voting intention. By means of quantitative research, two hundred and fifty questionnaires were distributed amongst students from the University of Witwatersrand. The findings indicate that five of the six hypotheses are insignificant with the exception of radio advertising. The results of this study provide political parties with a better understanding of the factors that prove to be ineffective when targeting Generation $Y$ consumers in South Africa. It further provides political parties with an opportunity to more successfully reach such individuals through other media platforms.
\end{abstract}

Keywords: Voting intention, advertising, convenience, social pressure, youth culture, South Africa

\section{Introduction}

Over the past decade, political parties have significantly increased the amount resources that they invest in political campaigns (Durante \& Gutierrez, 2014). Considering this statement, it is believed that by capitalizing on media expenditure, political parties can influence voting behaviour among people. However, empirical evidence is mixed in this respect (Durante \& Gutierrez, 2014). In light of this, political parties often underestimate the influence of other factors, such as candidate appeal (Ben-Ur \& Newman, 2002), registration convenience (Anderson \& Heath, 2003; Schulz, Zeh \& Quiring, 2005) and social pressures (Anderson \& Heath, 2003) on voting intention. This is especially relevant in a country like South Africa that has a controversial political history and where democracy is a relatively new phenomenon. Although a number of studies have been done on this topic, few have focussed on South Africa, which as an emerging economy, is often overlooked. For example, Han (2008) investigated the influence of media usage and sociodemographic factors in voting intention, and results indicated a significant relationship. Another study that focussed on media and its' influence on voting intention was conducted by Schulz, Zeh and Quiring (2005) and found that certain media does influence people's intention to vote. Furthermore, Ben-Ur and Newman (2002) investigated the impact that candidate or party morality has on voting intention and the findings revealed a significant relationship between these variables. Another variable that has been explored is the influence of convenience as a predicting variable on voting intention (Schulz, Zeh \& Quiring, 2005); however it primarily focussed on weather as an influencing factor. Schulz et al. (2005) broadened the scope on this topic by considering the impact of voter mobilisation on voting intention. And lastly, the influence of social group identities was investigated in a study by Anderson and Heath (2003).

Derived from the conceptions considered above, it is evident that little research has been conducted on this topic in a South African context. Therefore, by means of a proposed conceptual model, the present study explores the influence of advertising mediums, convenience factors and social pressures on voting intention. Although a number of factors that influence voting intention have been explored in other studies, the present study fills the gap in literature by providing political parties in South Africa with insight into the factors that 
influence people's voting intention. By getting a better understanding of such factors, political parties can utilise their resources and more accurately select their media channels for advertising. This will results in a higher return on investment, an increase in votes, and more profitable political parties. The present paper consists of sections presenting the literature review; research methodology, which includes the measurement instrument development and data collection procedure; the data analysis and results; discussion and implications of the study; a conclusion; limitations of the study; and suggestions for future research.

\section{Literature Review}

Theoretical Groundings: The present paper is grounded in Ajzen's $(2002,2011)$ theory of planned behavior (TPB) (Figure 1). The underlying conceptual foundation of this theory is that intention is the immediate antecedent of behavior, with attitude towards behavior, subjective norm and perceived behavior control acting as determinants of behavior intention.

\section{Figure 1: Theory of Planned Behaviour}

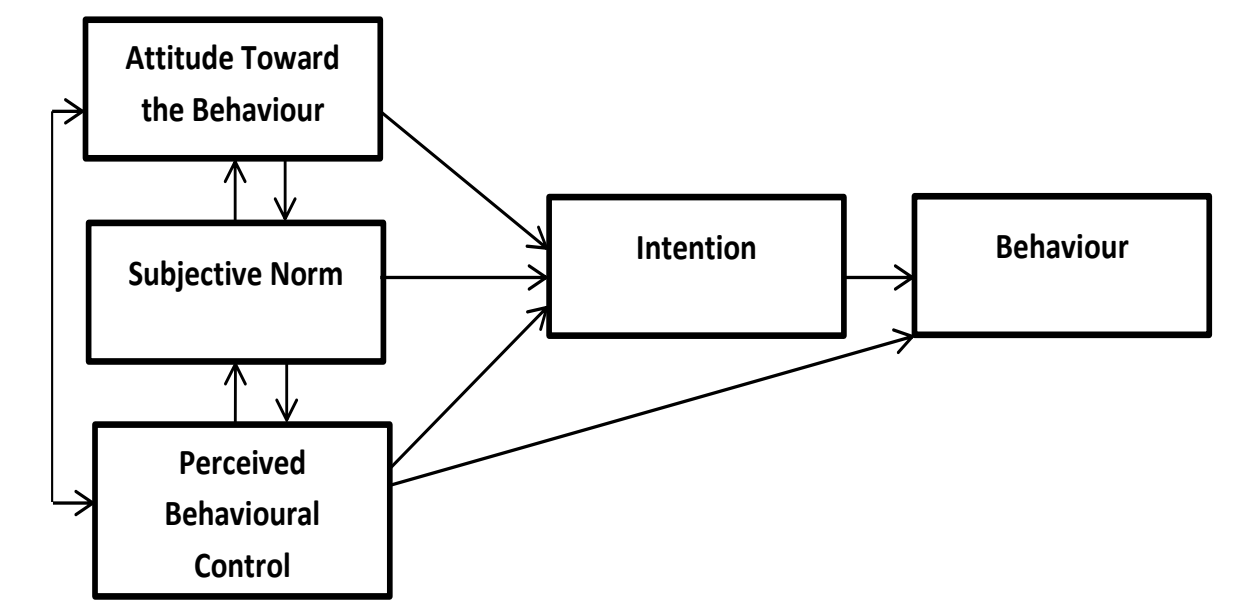

Source: Ajzen (1991)

The TPB is a commonly used theory that predicts behavioural intention and behavior. It shares the constructs of the theory of reasoned action (TRA), namely attitude and subjective norm, however it includes a third variable that accounts for perceived behavioural control. The latter variable is defined as the difficulty or ease of performing a particular behavior (Celuch and Dill, 2011) and can be closely linked to Bandura's (1998) concept of perceived self efficacy, which is the judgement of how well a person can perform a series of actions in order to handle a particular situation or address a particular behavior (Ajzen, 1991). The following section discusses the main components of the Theory of Planned Behaviour.

Attitude towards behaviour: Vaughan and Hogg (2005) define attitudes towards behaviour as a moderately enduring organization of beliefs, emotional state, and behavioral tendencies towards socially significant objects, groups, measures or symbols. More specifically, it refers to the degree to which an individual portrays a favourable to unfavourable evaluation of their intended behaviour. They will therefore consider the outcomes of performing the behaviour (Ajzen, 2011).

Subjective norm: Subjective norm is defined by Schepers and Wetzels (2007) as an individual's perception that most people who are of importance to that individual should or should not perform a particular behaviour in question. Subjective norm also refers to the normative views from the social setting that the individual is exposed to when performing a particular behaviour (Wolf, Weißenberger, Wehner and Kabst 2015). Numerous authors posited that and individual's attitude captures that individual's beliefs about outcomes and qualities of a certain behaviour (Montano, Kasprzyk, Glanz, Rimer and Viswanath, 2008; Wolf et al, 2015). The concept of the subjective norm particularly applies to the perceived social pressure that originates from people important to the individual (Montano et al, 2008). 
Perceived behavioural control: Perceived behavioural control is the independently perceived simplicity or difficulty of performing a particular behaviour Ajzen (2002). Perceived behavioural control refers to how simple or complex an individual thinks it is to perform behaviour (Lam and Hsu, 2006). This construct of the theory was added later, and distinguishes the Theory of Reasoned Action from the Theory of Planned Behavior.

Behaviour Intention: An individual's behavioral intention is defined as their planned or anticipated future behavior (Lam and Hsu, 2006). The relationship between perceived behavioral control and behavioral intention is based on the assumption that if perceived behavioral control increases, behavioral intention increases and that perceived behavioral control will affect behaviour directly to the degree that perceived control reflects actual control (Lam and Hsu, 2006).

\section{Empirical Literature}

Voting Intention: Intention refers to an individual's anticipated or premeditated future behavior Lam and Hsu (2006) and in the context of the present study, will refer to an individual's intention to vote at some future date. Newman (1999) developed a model for voter behaviour which the main purpose of analysing a voter motives, beliefs, attitudes and intentions (Ben-Ur \& Newman, 2002).It primarily aids in understanding how the state of a potential voters' mind influences the outcome of a political election. This is examined using "situational contingency" as the variable that denotes 'voters' thinking (Newman, 1999).

Factors influencing Voting Intention: Newman \& Sheth (1985) proposed a model with seven factors that potentially influence voters' choice behaviour (Figure 1). These are issues and policies; social imagery; emotional feelings; candidate image; current events; personal events; and epistemic issues. This model has, however, has received criticism due to the lack of including factors such as media and election Polls (Farrag \& Shamma, 2013). As a result, Farrag and Shamma (2013) proposed a revised model added the following factors as drivers of voting intention: family and friends influence, religious beliefs and media influence (Figure 2).

\section{Figure 2: Factors Influencing Voter Intentions}

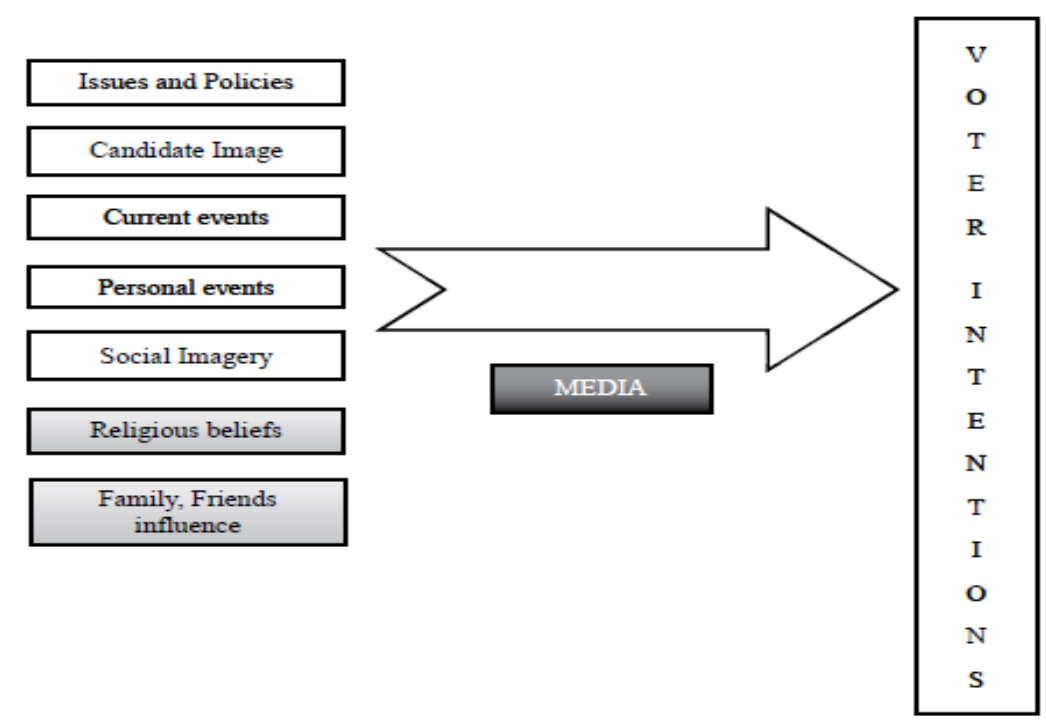

Source: Adopted from Newman and Sheth (1985, p. 179)

For the purpose of the present study, the following influential factors are used to measure voting intention: advertising mediums, convenience factors and social pressures. 
Advertising mediums: In practice, the concept of advertising is hard to define as it encompasses a broad range of viewpoints and philosophies. However, generally it is defined as any paid message or sponsor that is designed to promote an idea, goods or services for exchange Moriarty, Mitchell, Wells, Crawford, Brennan \& Spence-Stone, 2014). Furthermore, it involves either mass communication via newspapers, magazines, radio, television, and other media (e.g., billboards, bus stop signage) or direct-to-consumer communication via direct mail" (Richards \& Curran, 2002). Cwalina Falkowski \& Kaid (2005) highlighted that political advertising has an effect on voters' behaviour in a number of different ways. For instance, an advertisement may strengthen an individual's existing voting preference. It could also weaken an already existing voting preference. More importantly, an advertisement will neither weaken nor strengthen political voting behaviour, but may result in an individual's re-assessment of the candidate's image (Farrag \& Shamma, 2013). Franz et al., (2008) is of the opinion that the use television as a tool for political advertising has declined in recent years, and as a result, internet advertising is taking preference. Although, in South Africa, political parties remain to invest in mass media such as bill boards and television.

Convenience factors: Convenience is defined by Farquhar \& Rowley (2009) as the savings in time and effort by consumers in when purchasing products or goods. Considering that the present study focuses on location convenience, the following definition applies: providing a service to a customer at a place that minimizes the travel cost to the consumer (Jones et al., 2003). Jones et al. (2003) elaborates by explaining that travel cost refers to a fixed cost and entails the distance that the consumer must travel between his/her point of origin and the service provider. Location convenience also refers to a customer's perception of the effort and time needed to reach their service provider $(\mathrm{Wu}, 2011)$. Political parties have considered location convenience and its' impact on voting intention, and as a result, have invested in more convenience for voters by providing services such as electronic voting, voting by fax and absentee voting (Gronke et al., 2008). However, such convenience factors have not been fully utilized in South Africa. In a recent article by Presse (2014), statistics indicate that one in five South Africans were registered to vote for the 2014 elections. The present study aims to determine the relevance of location convenience on voting intention.

Social pressures: The issue of social pressure on the decision making of youth is something of significant interest. Social pressures refer to the motivation to blend in with a group's norms, characteristics and attributes (Huang, Phau \& Lin, 2008).According to Belanger and Eagles (2007), individuals exposed to contrasting views in their interpersonal relationships are likely to find themselves accountable to different constituencies, and therefore making it socially awkward for them to maintain strong views. Furthermore, the presence of a perceived threat from a source is likely to increase commonality and cohesion from the "threatened" group (Huang, Phau, \& Lin, 2008). Therefore, youth are most likely influenced by those with whom they interact with the most, and they could be either discouraged against voting or influenced on their decision when voting.

Conceptual Model and Hypotheses Development: By means of a comprehensive conceptual model, the present study aims to fill the gap in literature on factors influencing voting intention among Generation $\mathrm{Y}$ consumers in Johannesburg. The model proposes that advertising mediums (traditional, television and radio -advertising), convenience factors (convenience of registration process and location) and social pressures are the predictor variables, while voting intention is the outcome variable. Figure 3 presents the proposed conceptual model. 


\section{Figure 3: Proposed Conceptual Model}

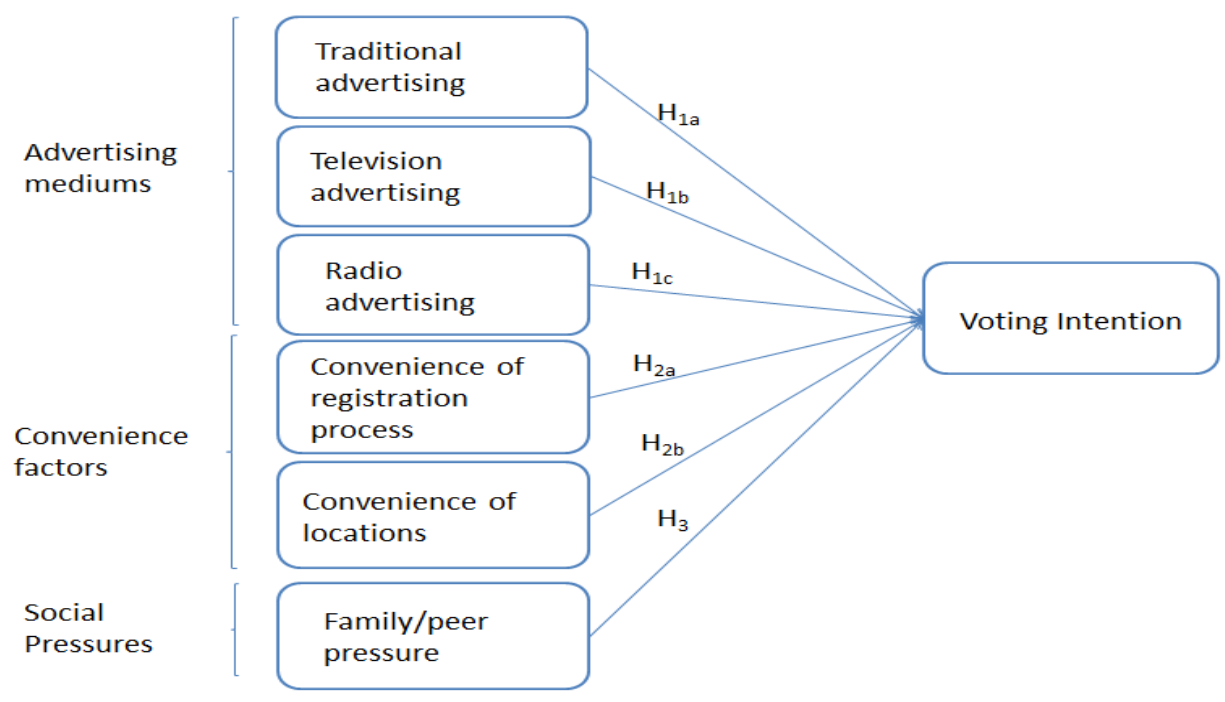

Note: TA=Traditional Advertising, TEA=Television Advertising, RA=Radio Advertising, RC=Registration Convenience, $\mathrm{LC}=$ Locational Convenience, $\mathrm{SP}=$ Social Pressures, VI=Voting Intention

\section{Hypotheses Development}

Advertising Mediums and Voting Intention: Although several facets of advertising influence voting intention (Ridout \& Franklin, 2012), the type of advertisement have a significant impact on voting behaviour (Cwalina et al., 2005). Farrag and Shamma (2013) state that political advertising may strengthen, weaken, voting intention, or have no influence on voter's behaviour. Furthermore, it is believed that the advertising source plays a prominent role in voter intention, and could also increase the effectiveness of the political advertisement (Yoon et al., 2005).Other studies have revealed that different forms of communication influence voting behaviour (Pfau et al., 2005). More specifically, the use of radio and television advertising is associated with greater political interest among voters and results in greater interest of presidential campaigns (Pfau et al., 2005). Although there has been a declined in televised political advertising campaigns, with a shift towards online advertising (Franz et al., 2008), traditional advertising is still used in South Africa. The present study therefore proposes the following:

$H_{1 a}$ : Traditional advertising has a positive influence on voting intention

$H_{1 b}$ : Television advertising has a positive influence on voting intention

$H_{1 c}$ : Radio advertising has a positive influence on voting intention

Convenience Factors and Voting Intention: Several studies on convenience factors and its' impact on consumer behaviour have been conducted, however, in contexts other than political advertising. For example, in a study conducted by $\mathrm{Wu}$ (2011) and Jones et al (2003), location convenience was found to have a significant impact of loyalty. Similary, it was found that location inconvenience of a service provider may lead to customer-switching behaviour ( $\mathrm{Wu}, 2011$; Lee \& Cunningham, 2001). Although voting may be regarded as a high involvement decision, Jones et al. (2003) state that location convenience is of more significant importance among low-involvement and routine services $(\mathrm{Wu}, 2011)$. Furthermore, the convenience of voting location outweighs the emotional attitude towards the service provider with regards to voting intention $(\mathrm{Wu}, 2011)$. In the context of this study, issues such as convenience of the actual registration process and the locations of registration venues and voting venues, could all have a significant impact on voting intention (Schulz, Zeh \& Quiring, 2005). Derived from the conceptions considered above, the present study therefore proposed the following hypotheses:

$H_{2 a}$ : Convenience of registration process has a positive influence on voting intention

$H_{2 b}$ : Convenience of locations has a positive influence on voting intention 
Social Pressures and Voting Intention: Social pressures are a large part to the choice of any consumer when making a decision to buy a product, and the same would go for the motives behind voters' behaviours, attitudes and intentions (Andersen \& Heath, 2003). Young adults are seen to negotiate social situations with "two competing goals in mind: preservation of a sense of independence while also operating safely within group norms in an attempt to maintain social bonds" (Glynn et al., 2009), and that their voting intentions would most definitely be influenced by "expectations and importance" of voting of primary groups such as family and close friends (Glynn et al., 2009).That is individuals are socially pressured on what their views are in politics, and supporter "cross-pressures is likely to discourage political participation" (Belanger \& Eagles, 2007).

$H_{3}$ : Social pressures have a positive influence on voting intention

\section{Research Design and Methodology}

A conclusive research approach was applied in which 250 self-administered surveys were distributed among a sample of university students. By means of a descriptive research method, the data gathering was preplanned and conducted using a quantitative research technique.

Sample and Data Collection: The target population for the study was students from the University of the Witwatersrand. The sample was drawn from the university campus by randomly selecting potential participants. Sample selection was conducted on both East and West campus in order to ensure the inclusion of a variety of students from different schools and faculties. The reason for having selected this target profile was that the Generation Y individual is regarded as the future consumer and more importantly, their voting behaviour will shape and predict the political future of this country.

Measurement Instrument and Questionnaire Design: A self-administered questionnaire was used for data gathering and existing scales were modified for the purpose of the present study. Five-point Likert scales were used for testing all the variables (1 - Completely Disagree; 2 - Disagree; 3 - Neutral; 4 - Agree; 5 Completely Agree).The questionnaire was first be preceded by a consent form and three screening questions to confirm participation of the target group. The questionnaire asked respondent's questions based on voting intention, with regard to the different predictor variables, that is traditional (print/billboard) advertising, television advertising, radio advertising, registration convenience, locational convenience, social pressures and voting intention. The first variable, namely advertising, was measured using a scale adapted from Saadeghvaziri, Dehdashti, \& Askarabad (2013) on web advertising. It consisted of questions relating to print, television and radio advertisements. The second variable, convenience, was measured using a scale adapted from Wu (2011) and Collier \& Sherrell (2010). The items were adapted to measure both locational convenience and the convenience of the registration process. The third variable, social pressures was measured using a scale adapted from a number of studies that include Huang, Ohau \& Lin's (2008) 'susceptibility to normative influence', which originates from an 8-item scale by Bearden et al. (1989). The scale used to measure voting intention was adapted from Levy \& Gendel-Guterman's (2012) 5-item purchase intention scale, as well as Glynn, Huge, \& Lunney's (2009) 2-item voting intention scale.

\section{Results}

The data analysis was done using SPSS 22 for the descriptive statistics, while the model fit and path modelling was conducted using AMOS 22.

Descriptive Statistics: Table 1 presents the respondent profile. 
Table 1: Respondent Profile

\begin{tabular}{ll}
\hline Descriptive Statistics & Percentages \\
\hline Gender & \\
Male & $43.6 \%$ \\
Female & $56.4 \%$ \\
Total & $100 \%$ \\
& \\
Age Category & \\
$18-24$ & $96 \%$ \\
$25-30$ & $3.2 \%$ \\
$31-35$ & $0.8 \%$ \\
Total & $100 \%$ \\
& \\
Home Language & \\
English & \\
Afrikaans & \\
Zulu & $44 \%$ \\
Tswana & $1.6 \%$ \\
Other (Majority Sotho \& Venda) & $16.4 \%$ \\
Total & $7.2 \%$ \\
\hline
\end{tabular}

The majority of the respondents (96\%) were between the ages of 18 and 24, with approximately half of them being females (56\%), and the rest males (44\%). The most common home language was English (44\%), followed by a number of African languages such as Sotho, Zulu and Xhosa.

Scale Accuracy Statistics: The results of scale reliability tests are shown in Table 2. As can be seen in table 3 above, the majority of the item-to-total values are above 0.6, while Cronbach's alpha coefficients $(\alpha)$, and composite reliability (C.R.) indexes ranged from 0.658 to 0.882 and 0.666 to 1.090 respectively. These values exceeded the estimate criteria suggested in prior literature. All average variance explained (AVE) values were above 0.4 and most approached 0.6, thus being acceptable according to the literature (Fraering \& Minor, 2006). These results reveal evidence of marginal to acceptable levels of research scale reliability.

Structural Equation Modeling: Structural equation modeling (SEM) is engaged in the current study for the purpose of analysing data. In recent times SEM has been established as a revered statistical technique to test theory in several fields of knowledge (Schumacker \& Lomax, 2004; Nusair \& Hua, 2010). Structural Equation Modeling (SEM) is applied to investigate on the hypothesised relationship in the research model (Liao \& Hsieh, 2013). Qureshi \& Kang (2015) defined Structural equation modeling as a multivariate statistical technique fundamentally engaged for analysing relationships between latent variables (or constructs) and observed variables that constitute a research model. 
Table 2: Accuracy Statistical Analysis

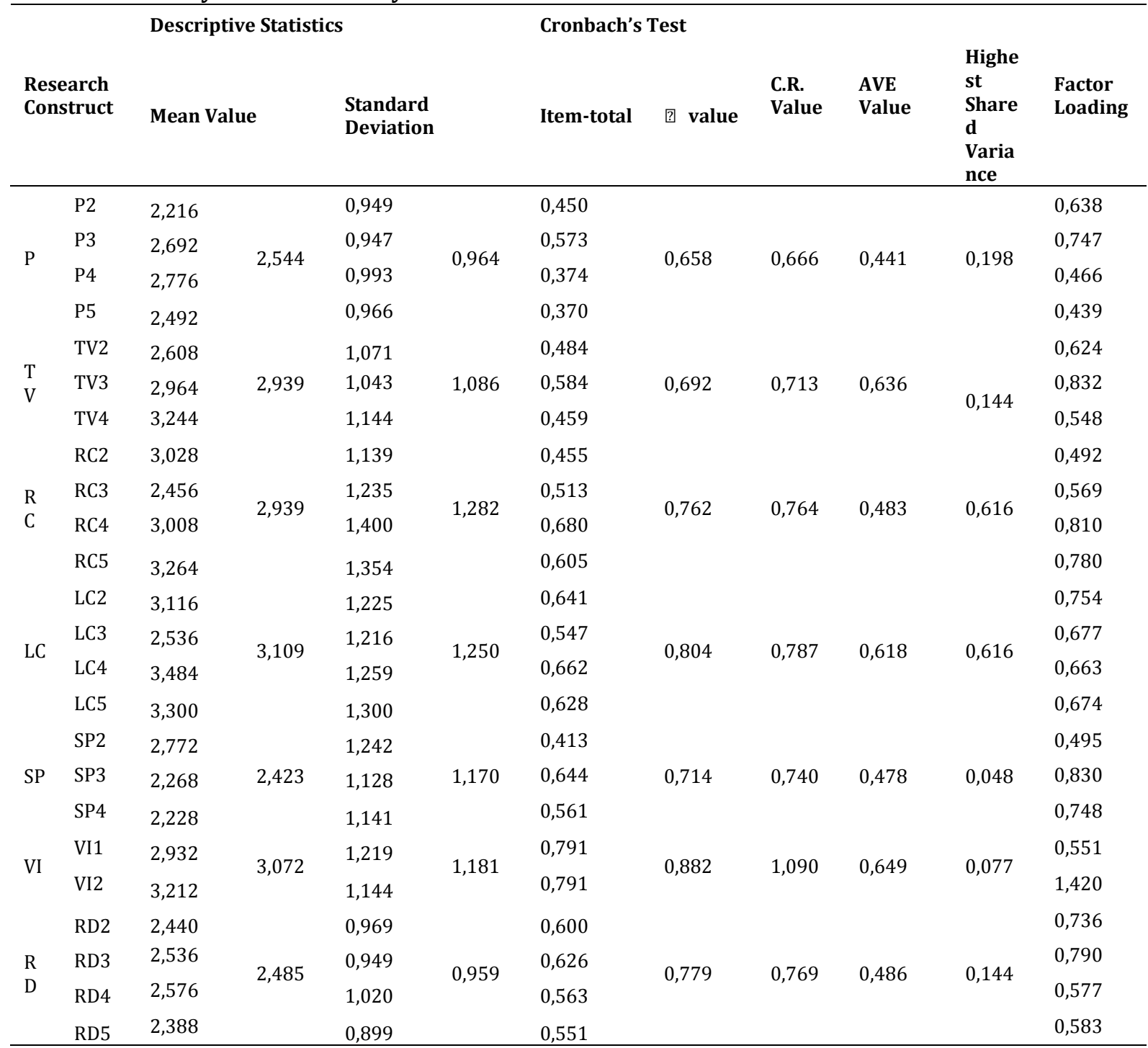

Note: TA=Traditional Advertising, TEA=Television Advertising, RA=Radio Advertising, RC=Registration Convenience, $\mathrm{LC}=$ Locational Convenience, $\mathrm{SP}=$ Social Pressures, VI=Voting Intention

Model Fit: The assessment of the proposed conceptual model proceeded utilising the unchanged data set. The ratio of chi-square over degree-of-freedom was 1,247. This value is less than the recommended thresshold of less than 3.0 and therefore, confirms the model fit (Chinomona \& Pretorius, 2011). Table 3 presents the model fit indices for the data.

Table 3: Model Fit Indices

\begin{tabular}{|c|c|c|c|c|c|c|c|c|}
\hline $\begin{array}{l}\text { Model fit } \\
\text { criteria }\end{array}$ & $\begin{array}{l}\text { Chi-square } \quad\left(\chi^{2}\right. \\
\text { /DF })\end{array}$ & GFI & CFI & TLI & IFI & RFI & NFI & RMSEA \\
\hline $\begin{array}{l}\text { Indicator } \\
\text { value }\end{array}$ & 1,247 & 0,925 & 0,980 & 0,972 & 0,980 & 0,873 & 0,907 & 0,031 \\
\hline
\end{tabular}


$\mathrm{CMIN} / \mathrm{DF}^{1}=2.47$ which is less than recommended $3, \mathrm{RMR}=0.086$ which is above the recommended 0.9 , $\mathrm{GFI}=0925$ which when rounded is equal to $0.9, \mathrm{AGFI}=0.88$ which is slightly less than 0.9 but greater than 0.8 , all suggest that there is model fit. Looking at the baseline comparisons, NFI $=0.907, \mathrm{RFI}=0.873, \mathrm{IFI}=0.980$, $\mathrm{TLI}=0.972$ and $\mathrm{CFI}=0.980$, which suggests that model fit is permissible. RMSEA is 0.031 which is a moderate fit and is marginally acceptable. CMIN/DF, RMR, GFI, and AGFI all suggest that there is not a good model fit. Looking at the baseline comparisons, NFI, RFI, IFI, TLI and CFI were all above 0.9 , and, which also suggests that the model fit is not very good.

Inter-construct Correlation Matrix: The inter-construct correlation matrix was utilized to check discriminant validity of the research constructs. Correlations among latent constructs were evaluated in order to observe if they were lower than 1.0. As indicated in table 2 below, the inter-correlation values for all paired latent variables are less than 1.0, therefore, indicating the existence of discriminant validity (Chinomona, Lin, Wang \& Cheng, 2010). Nunnally \& Bernstein (1994) recommended correlation values between constructs to be less than 0.7 in confirming the existence of discriminant validity. In Table 4 the inter-construct correlation matrix results is presented.

\section{Table 4: Inter-Construct Correlation matrix}

\begin{tabular}{llllllll}
\hline & $\mathbf{P}$ & TV & RC & LC & SP & VI & RD \\
\hline P & 1 & & & & & & \\
TV & 0,445 & 1 & & & & & \\
RC & 0,049 & 0,222 & 1 & & & & \\
LC & 0,021 & 0,206 & 0,785 & 1 & & & \\
SP & 0,202 & 0,177 & 0,200 & 0,214 & 1 & & \\
VI & 0,227 & 0,178 & $-0,137$ & $-0,135$ & 0,056 & 1 & \\
RD & 0,350 & 0,379 & $-0,048$ & $-0,009$ & 0,220 & 0,277 & 1 \\
**. Correlation is significant at the 0.01 level (2-tailed). & & & \\
*. Correlation is significant at the 0.05 level (2-tailed).
\end{tabular}

Path Modelling\& Hypotheses Testing: The path modeling and hypotheses results are presented in Table 5.

Table 5: Hypotheses Results

\begin{tabular}{lllll}
\hline Proposed Hypothesis Relationship & Hypothesis & $\begin{array}{l}\text { Path } \\
\text { Coefficients }\end{array}$ & $\begin{array}{l}\text { P } \\
\text { Value }\end{array}$ & Rejected/Supported \\
\hline Traditional Advertising (P) $\rightarrow$ Voting Intention (VI) & H1a & 0.06 & 0.07 & Supported but insignificant \\
Television Advertising (TV) $\rightarrow$ Voting Intention (VI) & H1b & 0.09 & 0.06 & Supported but insignificant \\
Radio Advertising (RAD) $\rightarrow$ Voting Intention (VI) & H1c & 0.17 & 0.05 & Supported and significant \\
$\begin{array}{l}\text { Registration Convenience }(\mathrm{RC}) \rightarrow \text { Voting Intention } \\
\text { (VI) }\end{array}$ & H2a & -0.05 & 0.96 & Unsupported but insignificant \\
Locational Convenience (LC) $\rightarrow$ Voting Intention (VI) & H2b & 0.04 & 0.37 & Supported but insignificant \\
Social pressures (SP) $\rightarrow$ Voting Intention (VI) & H3 & 0.10 & 0.07 & Supported but insignificant \\
\hline
\end{tabular}

Structural model fits: $\chi^{2} / \mathrm{df}=1,247 ; \mathrm{GFI}=0,925 ; \mathrm{CFI}=0,980 ; \mathrm{TLI}=0,972 ; \mathrm{IFI}=0,980 ; \mathrm{RFI}=0,873 ; \mathrm{NFI}=0,907$; RMSEA $=0,031$; ${ }^{\text {a }}$ significance level $\mathrm{p}<0.05{ }^{\mathrm{b}}{ }^{\mathrm{b}}$ significance level $<0.01{ }^{\mathrm{c}}{ }^{\mathrm{s}}$ significance level $<0.001$

\footnotetext{
${ }^{1}$ Note: Chi-square test (CMIN/DF), Root Mean Square Residual (RMR), Goodness of fit index (GFI), Adjusted Goodness of Fit Index (AGFI), Normed fit index (NFI), Relative Fit Index (RFI), Incremental fit index (IFI), Tucker Lewis index (TLI), Comparative fit index (CFI) and Random Measure of Standard Error Approximation (RMSEA).
} 
Upon examining H1a (the influence of traditional advertising on voting intention) andH1b (the influence of television advertising on voting intention), the results for both reveal positive relationships implying that these relationships are supported. Therefore we fail to reject the hypotheses. However, the p-values are greater than 0.05 indicating that these relationships are not significant. Thus we can observe, from the results of $\mathrm{H} 1 \mathrm{a}$ and $\mathrm{H} 1 \mathrm{~b},(0.06)$ and $(0.09)$ respectively that traditional advertising (billboards and posters) and television advertising do not influence voting intention. On the other hand, H1c (the influence of radio advertising on voting intention), indicate that the hypothesis is supported and significant (the p-value is 0.05 and path coefficient 0.17 ). Thus, radio advertising has a significant influence on voting intention. The results of the second hypothesis ( $\mathrm{H} 2 \mathrm{a})$, which tested the influence of registration convenience on voting intention, indicated a path coefficient of -0.05 .Therefore, registration convenience is inversely related to voting intention. This relationship is not supported and we to fail to reject the null hypothesis. In other words, although the registration process is convenient, this does not influence the youth to vote. The path coefficient for $\mathrm{H} 2 \mathrm{~b}$ (the influence of locational convenience on voting intention) is 0.04 , which indicates that locational convenience is positively related to voting intention. This relationship is supported therefore we to fail to reject the hypothesis. In other words, even though the access to the location is convenient, this does not influence whether the young will vote or not. Lastly, hypothesis 3 (H3), which tested the influence of social pressures on voting intention, has a path coefficient of 0.10 . This relationship is supported therefore we to fail to reject the hypothesis. This means that social pressures do not influence voting intention.

\section{Conclusion and Discussion}

The purpose of this study was to investigate the influence of advertising mediums, convenience of registration and location, as well as social pressures on voting intention among the youth in South Africa. In particular, six hypotheses were postulated and data was collected from University of Witwatersrand in the Gauteng province of South Africa. Five of the six hypotheses yielded significant relationships. Firstly, the findings indicate that traditional advertising mediums such as billboards and posters as well as television advertising do not influence voting intention. The only advertising medium that has significant influence on voting intention is radio advertising. These results are partly consistent with previous studies on advertising mediums and voting attitudes. For example, Franz et al. (2008) stated that political advertising is shifting from the traditional mediums to internet advertising. It is therefore vital in future to find more specific ways of grasping the attention of the youth. The second factor, namely registration convenience, was supported, however with an inverse relationship. Therefore, the convenience of the registration process has shown that it impacts voting intention of youth, but in an inverse relationship. Therefore indicates that registration convenience will not lead to voting intention. Further, it is evident that location convenience does not influence voting intention. On other words, even if marketers provide convenience in terms of the registration process and access to the location, voters are unlikely to consider voting. This is inconsistent with previous studies which indicate that the more convenience locations are, the more likely that individuals will intend to vote (Schulz, Zeh \& Quiring, 2005; Wu, 2011).Likewise, social pressures do not influence voting intentions. Therefore, by targeting family and friends of the potential voters, it is unlikely that the youth's voting intention will increase. This is inconsistent with previous studies that found a significant relationship between social pressures and voting intention (Belanger \& Eagles, 2007; Glynn et al., 2009).

Managerial Implications of the Study: The results of this study offer significant implications for marketing managers of political campaigns in South Africa. According to the findings, most of the efforts by marketing managers should be geared towards radio advertising as this was seen to have the strongest influence on youth's intention to vote. Campaign managers can achieve this by purchasing air time on radio stations that are tailored for the youth and partnering with educational institutions that have radio stations in order to broadcast their political messages. With the exception of radio advertising, it was seen that other forms of traditional advertising do not have a significant impact on the youth's voting. This implies that managers of political campaigns may achieve better election turnouts if they consider modern advertising such as mobile or internet advising to reach the younger audience. Through providing convenience to voters, political managers and marketers are unlikely to achieve high voter outcomes. Likewise, it may not be feasible to invest in methods that will target the peers of the voters. 
Limitations \& Future Research: Although this study contributes to literature in a number of ways, there are potential limitations. Firstly, only a few advertising mediums were focused on, specific political parties could not be used to specifically distinguish the general success of marketing campaigns, and most of the respondents fell between the age-group 18-24 due to the target population. From this study, many insights can be taken out, such as the fact that youth in South Africa are not impacted by these traditional means of advertising. Therefore, for further research, other means of advertising should be taken into consideration, such as online channels (which are currently being used by certain parties in South Africa), as most youth are exposed to online platforms, as seen from studies done overseas. A more in-depth look can be taken on campaign strategies, specifically for the political parties that are of prominence in the country. Convenience of registration process was seen to impact voter intention negatively, therefore should be excluded in further studies. Convenience of locations on the other hand influenced voting intention; therefore an in-depth look can be done on convenience, such as a convenience voting study, as done in other countries, in order to determine the exact influencers with regard to convenience. Social pressures have been seen to influence voting intention of youth negatively; therefore it is a vital variable to be considered, especially within a South African perspective, and possibly a wider range of questions could be used in order to specifically determine who influences youth more, in a negative capacity and also what the reasons may be behind that.

\section{References}

Ajzen, I. (1991). The theory of planned behaviour. Organisational Behavioural and Human Decision Process, $50,179-211$.

Ajzen, I. (2002) Perceived Behavioral Control, Self-Efficacy, Locus of Control, and the Theory of Planned Behavior. Journal of Applied Social Psychology, 32, (4), 665-683.

Ajzen, I. (2011). The theory of planned behavior: Reactions and reflections. Psychology \& Health, 26(9), 11131127.

Anderson, R. \& Heath, A. (2003). Social identities and political cleavages: the role of political context. Journal of the Royal Statistical Society: Series A (Statistics in Society), 166(3), 301-327.

Bandura, A. (1998). Social cognitive theory and self-efficacy. Personality, 1, 384.

Bearden, W. O., Netemeyer, R. G. \& Teel, J. E. (1989). Measurement of consumer susceptibility to interpersonal influence. Journal of Consumer Research, 15(4), 345-356.

Belanger, P. \& Eagles, M. (2007). Partisan Cross-Pressure and VoterTurnout: The Influence of Micro and Macro Environments. Social Science Quarterly, 88(3), 851-867.

Ben-Ur, J. \& Newman, B. I. (2002). Motives, Perceptions and Voting Intention of Voters in the 2000 U.S.Presidential Election. Psychology \& Marketing, 19(12), 1047-1065. doi: 10.1002/mar. 10052.

Celuch, K. \& Dill, A. (2011). An Extension of the Theory of Reasoned Action in Ethical Decision Contexts: The Role of Normative Influence and Ethical Judgment. Journal of Education for Business, 86, 201-207.

Chinomona, R., Lin, J. Y. C., Wang, M. C. H. \& Cheng, J. M. S. (2010). Soft power and desirable relationship outcomes: the case of Zimbabwean distribution channels. Journal of African Business, 11(2), 182-200.

Chinomona, R. \& Pretorius, M. (2011). Major dealers' expert power in distribution channels. South African Journal of Economic and Management Sciences, 14(2), 170-187.

Collier, J. E. \& Sherrell, D. L. (2010). Examining the influence of control and convenience in a self-service setting. Journal of the Academic Marketing Science, 38, 490-509. doi:10.1007/s11747-009-0179-4.

Cwalina, W., Falkowski, A. \& Kaid, L. L. (2005). Advertising and the image of politicians in evolving and established democracies: Comparative study of the Polish and the US presidential elections in 2000. Journal of Political Marketing, 4(2-3), 19-44.

Durante, R. \& Gutierrez. (2014). Political Advertising and voting intentions: Evidence from exogenous variation in ads viewership. Research paper (July, 2014).

Farrag, D. A. R. \& Shamma, H. (2013). Factors influencing voting intentions for Egyptian parliament elections 2011. Journal of islamic Marketing, 5(1),49-70. doi: 10.1108/JIMA-01-2013-0003.

Farquhar, J. D. \& Rowley, J. (2009). Convenience:a services perspective. Marketing Theory, 9(4), 425-438. doi: $10.1177 / 1470593109346894$.

Franz, M. M., Freedman, P., Goldstein, K. \& Ridout, T. N. (2008). Understanding the Effect of Political Advertising on Voter Turnout: A Response to Krasno and Green. Journal of Politics, 70(1), 262 -268. doi: 10.1017/S0022381607080188. 
Glynn, C. J., Huge, M. E. \& Lunney, C. A. (2009). The Influence of Perceived Social Norms on College Students' Intention to Vote. Political Communication, 26, 48-64. doi: 10.1080/10584600802622860.

Gronke, P., Galanes-Rosenbaum, E., Miller, P. A. \& 1 Toffey, D. (2008). Convenience Voting. Annual Review of Political Science, 11, 437-455. doi: 10.1146/annurev.polisci.11.053006.190912.

Han, G. K. (2008). New Media Use, Sociodemographics. Mass Communication \& Society, 11, 62-81. doi: $10.1080 / 15205430701587644$.

Huang, Y., Phau, I. \& Lin, C. (2008). Consumer animosity, economic hardship, and normatve influence. European Journal of Marketing, 44(7/8), 909-937. doi: 10.1108/03090561011047463

Jones, M. A., Mothersbaugh, D. L. \& Beatty, S. E. (2003). The effects of locational convenience on customer repurchase intentions across service types. Journal of Services Marketing, 17(7), 701-712. doi: 10.108/08876040310501250.

Lam, T. \& Hsu, C. H. (2006). Predicting behavioral intention of choosing a travel destination. Tourism Management, 27(4), 589-599.

Lee, M. \& Cunningham, L. F. (2001). A cost/benefit approach to understanding service loyalty. Journal of services Marketing, 15(2), 113-130.

Levy, S. \& Gendel-Guterman, H. (2012). Does advertising matter to store brand purchase intention?. Journal of Product \& Brand Management, 21(2), 89-97.

Liao, C. H. \& Hsieh, I. Y. (2013). Determinants of consumer's willingness to purchase gray-market smartphones. Journal of business ethics, 114(3), 409-424.

Montano, D. E., Kasprzyk, D., Glanz, K., Rimer, B. K. \& Viswanath, K. (2008). Theory of reasoned action, theory of planned behavior, and the integrated behavioral model. Wiley, USA

Moriarty, S., Mitchell, N. D., Wells, W. D., Crawford, R., Brennan, L. \& Spence-Stone, R. (2014). Advertising: Principles and Practice. $3^{\text {rd }}$ ed. Australia: Pearson.

Newman, B. I. \& Sheth, J. N. (1985). A model of primary voter behavior. Journal of Consumer Research, 3, 178187.

Newman, B. I. (1999). A predictive model of voter behavior: The repositioning of Bill Clinton. Handbook of political marketing, 1, 159-173.

Nunnally, J. C. \& Bernstein, I. H. (1994). The assessment of reliability. Psychometric theory, 3, 248-292.

Nusair, K. \& Hua, N. (2010). Comparative assessment of structural equation modeling and multiple regression research methodologies: E-commerce context. Tourism Management, 31(3), 314-324.

Pfau, M., Houston, J. B. \& Semmler, S. M. (2005). Presidential Election Campaigns and American Democracy. The American Behavioral Scientist, 49(1), 48-62. doi: 10.1177/0002764205279429.

Presse, A. F. (2014). Record number of South Africans register to vote. (2014, February). News Daily.

Richards, J. I. \& Curran, C. M. (2002) Oracles on Advertising: Searching for a Definition. Journal of Advertising, 31(2), 63-77, doi: 10.1080/00913367.2002.10673667

Qureshi, S. M. \& Kang, C. (2015). Analysing the organizational factors of project complexity using structural equation modelling. International Journal of Project Management, 33(1), 165-176.

Ridout, T. N. \& Fowler, E. F. (2012). Explaining Perceptions of Advertising Tone. Political Research Quarterly, 65(1), 62-75.

Saadeghvaziri, F., Dehdashti, Z. \& Askarabad, M. R. K. (2013). Web advertising: Assessing beliefs, attitudes, purchase intention and behavioral responses. Journal of Economic and Administrative Sciences, 29(2), 99-112.

Schepers, J. \& Wetzels, M. (2007). A meta-analysis of the technology acceptance model: Investigating subjective norm and moderation effects. Information \& Management, 44(1), 90-103.

Schulz, W., Zeh, R. \& Quiring, O. (2005). Voters in a Changing Media Environment. A Data-Based Retrospective on Consequences of Media Change. European Journal of Communication, 20(1), 55-88.

Schumacker, R. E. \& Lomax, R. G. (2004). A beginner's guide to structural equation modeling. Psychology Press. New Jersey, USA

Voter turnout in the 20th century. National election patterns and their implications. (2000, October). Congressional Digest, 226 and 256.

Wolf, S., Weißenberger, B. E., Wehner, M. C. \& Kabst, R. (2015). Controllers as business partners in managerial decision-making: Attitude, subjective norm, and internal improvements. Journal of Accounting \& Organizational Change, 11(1), 24-46.

$\mathrm{Wu}, \mathrm{L}$. (2011). Beyond satisfaction. The relative importance of locational convenience, interpersonal relationships, and commitment across service types. Managing Service Quality, 21(3), 240-263. 
Vaughan, G. \& Hogg, M. A. (2005). Introduction to social psychology. Pearson Education Australia.

Yoon, K., Pinkleton, B. E. \& Ko, W. (2005). Effects of Negative Political Advertising on Voting Intention: An Exploration of the Roles of Involvement and Source Credibility in the Development of Voter Cynicism. Journal of Marketing Communications, 11(2), 95-112. 